\title{
Sustainable Measures for Protection of Structures Against Earthquake Induced Liquefaction
}

\author{
Gopal S. P. Madabhushi1 ${ }^{1}$ (D) Samy Garcia-Torres ${ }^{1}$
}

Received: 27 September 2020/Accepted: 8 April 2021/Published online: 25 April 2021

(C) The Author(s) 2021

\begin{abstract}
Soil liquefaction can cause excessive damage to structures as witnessed in many recent earthquakes. The damage to small/medium-sized buildings can lead to excessive death toll and economic losses due to the sheer number of such buildings. Economic and sustainable methods to mitigate liquefaction damage to such buildings are therefore required. In this paper, the use of rubble brick as a material to construct earthquake drains is proposed. The efficacy of these drains to mitigate liquefaction effects was investigated, for the first time to include the effects of the foundations of a structure by using dynamic centrifuge testing. It will be shown that performance of the foundation in terms of its settlement was improved by the rubble brick drains by directly comparing them to the foundation on unimproved, liquefiable ground. The dynamic response in terms of horizontal accelerations and rotations will be compared. The dynamic centrifuge tests also yielded valuable information with regard to the excess pore pressure variation below the foundations both spatially and temporally. Differences of excess pore pressures between the improved and unimproved ground will be compared. Finally, a simplified 3D finite element analysis will be introduced that will be shown to satisfactorily capture the settlement characteristics of the foundation located on liquefiable soil with earthquake drains.
\end{abstract}

Keywords Drains · Earthquakes · Ground Improvement . Sustainability

Gopal S. P. Madabhushi

mspg1@cam.ac.uk

1 Schofield Centre, Department of Engineering, University of Cambridge, Cambridge, UK

\section{Introduction}

In geotechnical engineering novel but economic solutions are sought for a wide range of problems from retaining walls to earth dams. Innovative use of materials is also encouraged especially when such innovations are attractive from an economic point of view. Use of sustainable materials within geotechnical engineering such as use of fly ash or lime stabilisation of weak clayey soils are good examples of intersections of sustainability and economics. However, when structures are subjected to earthquake loading, design has been driven by the safety and integrity of the structures in the post-seismic period. Innovations have been confined largely to methods of reducing the seismic loads acting on the structures. For example, allowing a structure to rock or designing the foundations that encourage a structure to rock have been investigated [1-4]. This is a significant shift from seismic design of structures where the structure is assumed to be fixed to the ground and geotechnical engineers are required to design strong foundations that afford 'near full fixity' of the structure at the ground level. Increasingly with the advent of performance-based design, it is becoming apparent in geotechnical earthquake engineering, it is beneficial to consider the foundation soil carefully and take advantage of any soil deformations, as is the case with allowing foundations to rock within certain performance limits.

In addition to the economic gains of placing less stringent demands on the foundation by insisting on 'near full fixity', the soil deformations also have the added benefit of adding damping to the system. Soil damping is significantly larger and is therefore able to dissipate a significant proportion of energy directed towards the structure by the earthquake event. Previously Jabary and Madabhushi [5] have demonstrated using dynamic centrifuge testing that 
when structures are fitted with Tuned Mass Dampers (TMD's) the dampers must be tuned considering dynamic soil-structure interaction. It was also shown that significant damping is afforded by the foundation soil that can be beneficial in reducing the earthquake-induced vibrations in portal frame structures. More recently Boksmati and Madabhushi [6] studied model structures fitted with viscous dampers and tracked the energy dissipation in the viscous dampers as well as in the foundation soil. They concluded that dynamic soil-structure interaction and consequent damping in the foundation soil can benefit the overall structural performance during a seismic event. Utilising the foundation soil in the design through better understanding the dynamic characteristics of the soil can lead to more economic and sustainable solutions in earthquake engineering.

In this paper, the focus will be on the particularly challenging aspect of soil liquefaction that is a consequence of strong ground motion. A large number of structures, port facilities, water front structures, etc. are vulnerable from a liquefaction point of view. Past earthquakes have provided many examples of severe damage to structures following liquefaction as will be illustrated in next section. There is an urgent need to develop economic and sustainable liquefaction mitigation measures that are well tested and proven for their efficacy. In this paper, liquefaction mitigation using drains will be considered. The novelty of the paper is in the use of sustainable material such as construction debris, brick rubble, etc. that could be used to construct drains in loose, saturated sandy or silty soils that are vulnerable from a liquefaction point of view. Such drains can be economical as they use waste material such as construction debris that can even come from previous earthquake-damaged structures or due to demolition activities. Instead of landfilling such construction debris, use of this material in constructing drains in a particular area is a sustainable alternative for developing low-cost, low-rise residential buildings that are protected against liquefaction.

\section{Earthquake Induced Liquefaction}

The Christchurch earthquakes of 2011 and 2012 have created wide spread liquefaction in the suburbs of Christchurch city along the banks of river Avon. Relatively modest structures like the one shown in Fig. 1 have suffered settlement and rotation due to soil liquefaction. Many of these structures had to be destroyed and large populations from the suburbs of Christchurch had to be relocated into 'safer' areas from a future earthquake safety point of view.

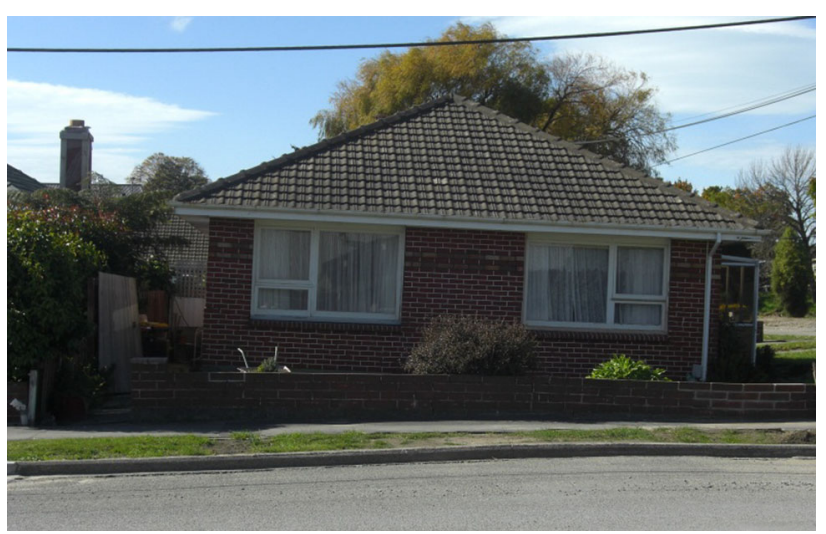

Fig. 1 Settlement and rotation of a residential structure following Christchurch earthquake of 2012

More recently, Palu earthquake of 2018 in Indonesia has provided a vivid example of wide spread soil liquefaction. A vast number of residential buildings were destroyed due to a liquefaction-induced lateral spreading event. In Fig. 2 the pre-earthquake and post-earthquake satellite images of a region of Palu are shown, which clearly indicate complete destruction of the structures in this area. The ground situation also shows widespread destruction of the houses due to this soil liquefaction-induced lateral spreading event as illustrated in Fig. 3.

Although structures such as the ones seen in Figs. 1 and 3 are relatively common, simple structures, they need protection against liquefaction. This is because of the large number of such structures that can be damaged with the consequent human death toll and economic damage. Also it may be more economical to design and implement liquefaction mitigation measures at a ward, block or city level, rather than attempting to provide liquefaction mitigation for individual dwellings. Equally, existing structures may also need protection against liquefaction. These will be considered in lateral sections of this paper.

In this paper, the focus will be on mitigating liquefaction risk to the structures using earthquake drains, especially for existing structures that are identified to be on liquefiable ground. In Fig. 4, the construction of drains is demonstrated schematically. It is possible to construct vertical drains around the perimeter of an existing structure. Additional sacrificial rings of drains can be constructed to ensure higher efficiency of internal drains following Brennan and Madabhushi [7]. With the advances in directional drilling, it is now possible to construct inclined drains below existing structures as shown in Fig. 4. GarciaTorres and Madabhushi [8,9] have investigated the performance of vertical and inclined drains. It will be shown later in this paper that it is preferable to have inclined drains to reduce the drainage distance between the 


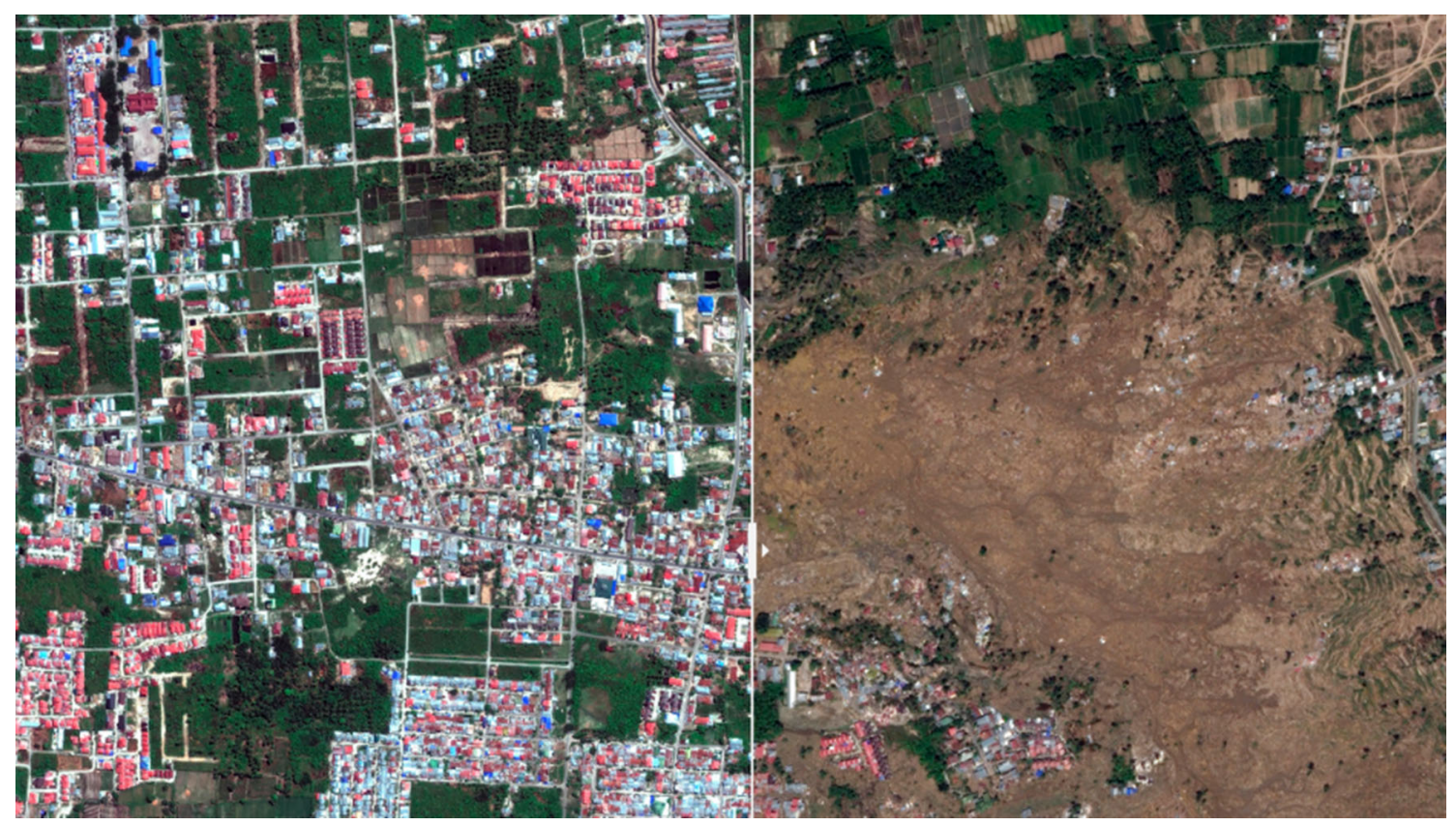

Fig. 2 Pre and Post-earthquake satellite images of the destruction due to lateral spreading

Fig. 3 Ground based image showing the destruction due to lateral spreading

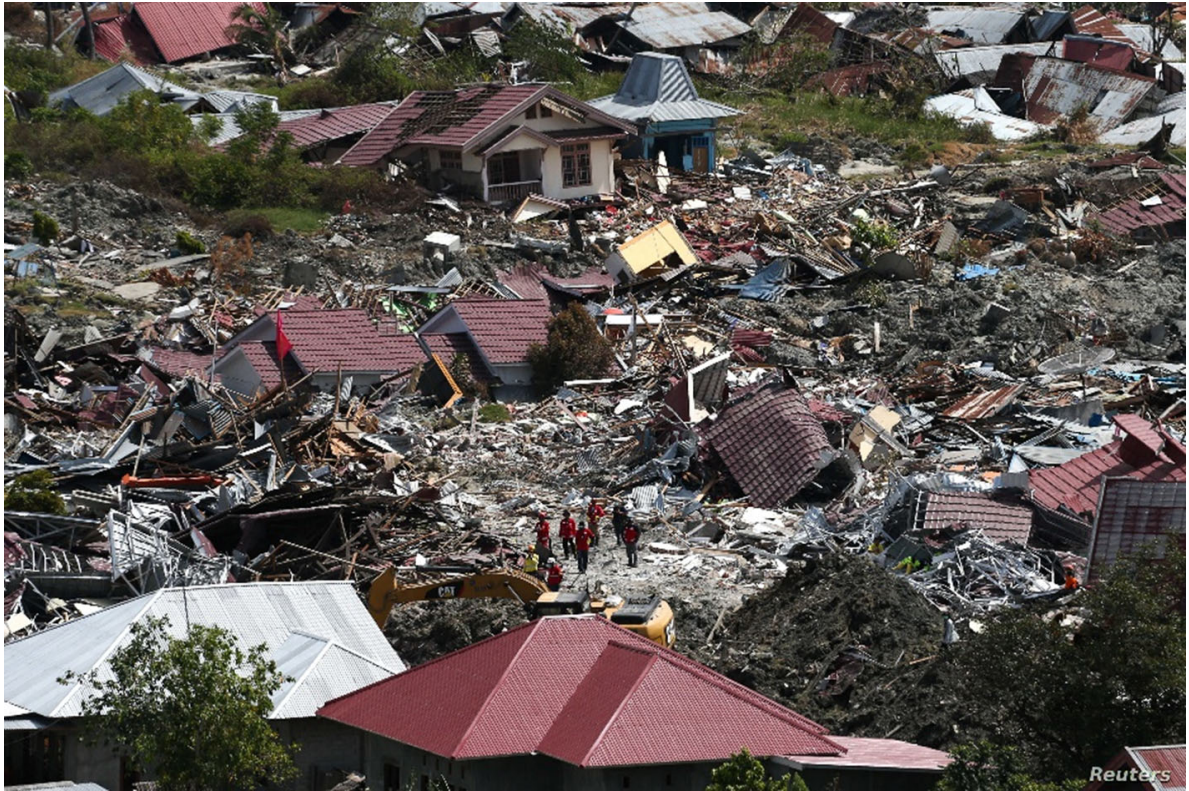

foundation soil below a structure and the earthquake drain to improve their performance.

Research on earthquake drains as a liquefaction mitigation method started in early 1970 's. Seed and Booker [10] have developed a design method for the use of earthquake drains by considering the concept of a 'unit cell' with a single drain and surrounding liquefied soil it mitigates and specified the drain spacing. This method is largely used in the industry, for example, Raju et al. [11] who give many examples of their use in Asia. Previous research on earthquake drains using dynamic centrifuge testing was reported by Madabhushi and Brennan $[7,12,13]$. Their research was focussed primarily on improving horizontal, liquefiable ground and understanding the effects of drain location on their ability to relieve excess pore pressures. A new drain classification based on location was developed and the concept of 'perimeter' and 'semi-perimeter' drains was introduced. This research has been followed up with centrifuge testing to demonstrate the efficacy of pre-fabricated drains [14]. Olarte et al. [15] used centrifuge testing to demonstrate the efficacy of the combination of drainage and densification. Shenthen et al. [16] 
Fig. 4 Schematic diagram showing vertical and inclined drains below a structure

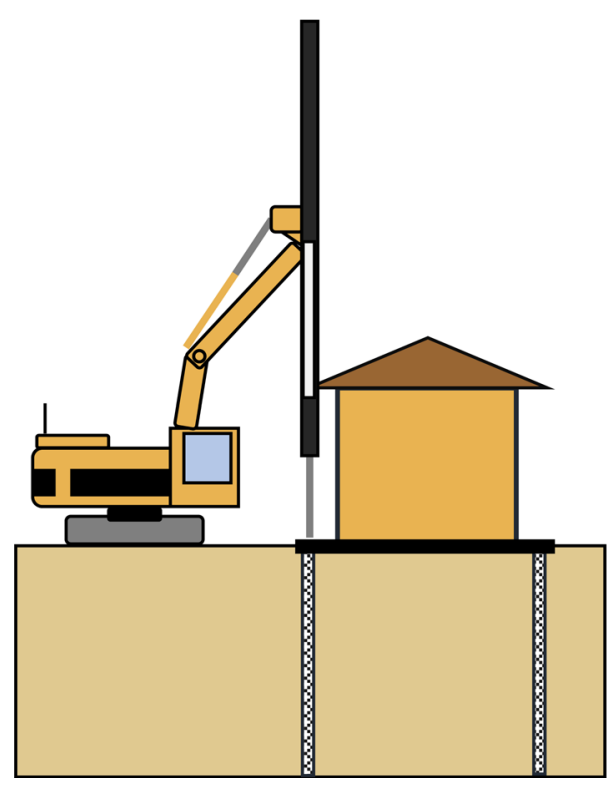

Vertical perimeter drains

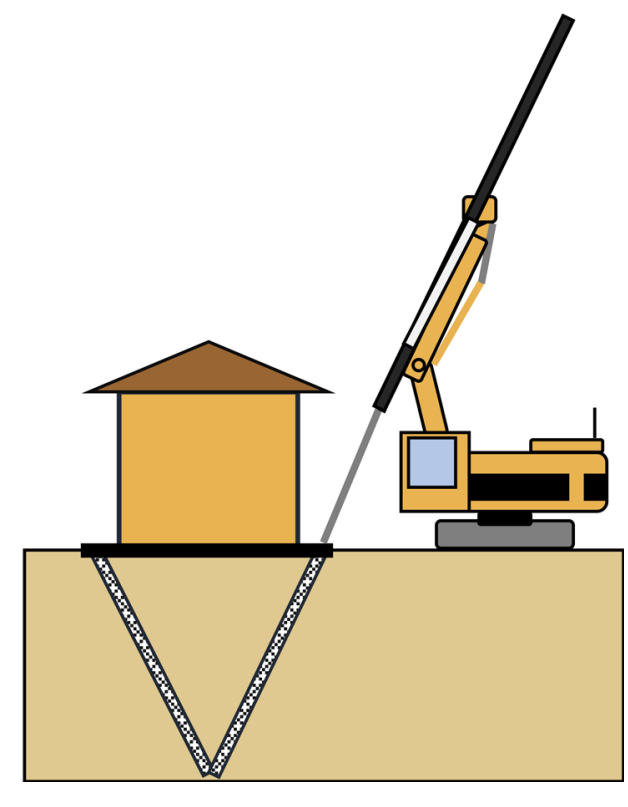

Inclined perimeter drains used shaking table test facility at Suny-Buffalo to investigate the performance of stone columns combined with densification as liquefaction mitigation measure in silty sands. Orense [17] discusses the use of earthquake drains as one of the liquefaction mitigation measures.

The use of sustainable materials for constructing earthquake drains is growing in recent years. The performance of wall gravel drains containing recycled concrete was evaluated as a mitigation technique for buried structures, using shaking table tests [18]. A decrease in the structure uplift was obtained due to the rapid dissipation of excess pore pressures below the structure. In addition, shaking table tests were carried out to examine the behaviour of rubber and gravel columns in liquefiable soil [19]. The granular columns provided a greater reduction of the free field deformation compared with the rubber columns; however, for a higher input motion and density, an improved performance of the rubber drains was observed. Furthermore, non-reinforced and reinforced backfill for a quay wall were analysed using shaking table tests [20]. The treated backfill considered a cushion and vertical drains made of tier chips. Results verified the effectiveness of the proposed mitigation method, as a decrease of the seismic load and structural displacement was observed. Numerical modelling of drains containing reused material was performed by Abdullah and Hazarika [21]. Soil improvement, considering vertical drains with coir dust and sea sand inside, was evaluated by Kumara et al. [22]. In this paper, a comparison between improved and unimproved soft clay was developed using laboratory consolidation tests.

\section{Advanced Experimental Testing in Geotechnical Earthquake Engineering}

While examples of real earthquake damage provided in previous section of this paper demonstrate the importance of the problem of soil liquefaction, they provide very little information in terms of enhancing the understanding about liquefaction or the efficacy of any mitigation measures. In order to investigate soil liquefaction carefully and develop liquefaction mitigation methods, advanced experimental testing is required. While cyclic triaxial tests provide interesting and valuable information regarding soil behaviour close to liquefaction, it is not possible to use such testing to investigate boundary value problems.

Geotechnical centrifuge testing offers a way forward. In centrifuge modelling, prototype stresses and strains are generated in small-scale physical models by subjecting them to enhanced gravity [23]. Further powerful earthquake actuators are required to subject the soil models inflight to strong earthquake-like shaking to create soil liquefaction. In this section, the facilities that are available at the Schofield Centre, University of Cambridge are described. In Fig. 5, the Cambridge Turner beam centrifuge is shown. This centrifuge is a $150 \mathrm{~g}$-tonne machine, with a diameter of $10 \mathrm{~m}$. However, for earthquake loading tests its operation is restricted to $80 \mathrm{~g}$ 's due to additional stresses created by the dynamic forces during earthquake loading.

Previously earthquake loading was modelled using a mechanical earthquake actuator called the Stored Angular Momentum (SAM) earthquake actuator [24]. In the last decade a new, servo-hydraulic earthquake actuator was developed [25]. A view of the servo-hydraulic earthquake 
Fig. 5 A view of the $10 \mathrm{~m}$ diameter Turner Beam Centrifuge

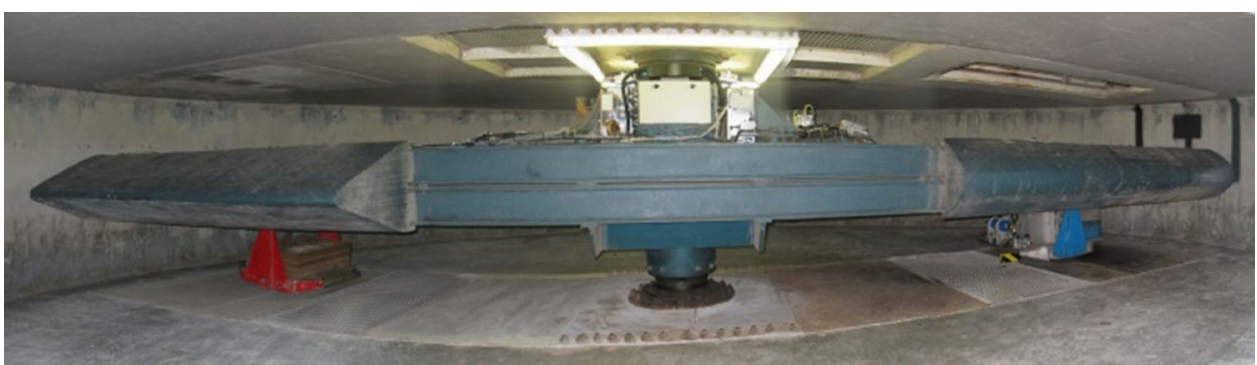

actuator is shown in Fig. 6. In this figure, a level bed of sand that was mounted on the shaking table and subjected to earthquake motions is also seen. This level bed is constructed in a specialist model container called the Equivalent Shear Beam (ESB) container that minimises the lateral reflections from the boundaries normal to the direction of shaking [26]. The main advantage of this earthquake actuator is that it can simulate more realistic earthquake motions. An example of the earthquake motions produced by this earthquake actuator during a $50 \mathrm{~g}$ centrifuge test is shown in Fig. 7. In Fig. 7a, b, scaled Kobe motion and Imperial Valley motion are shown along with their FFT's to help identify various frequency components. Although these motions are extensively used at Cambridge, it is possible to programme in other input motions that researchers may desire.

The dynamic centrifuge tests presented in this paper on earthquake drains were all carried out using the servo-hydraulic earthquake actuator at $50 \mathrm{~g}$ 's of centrifugal acceleration. In these tests a series of earthquakes were modelled including the sinusoidal earthquake motions and

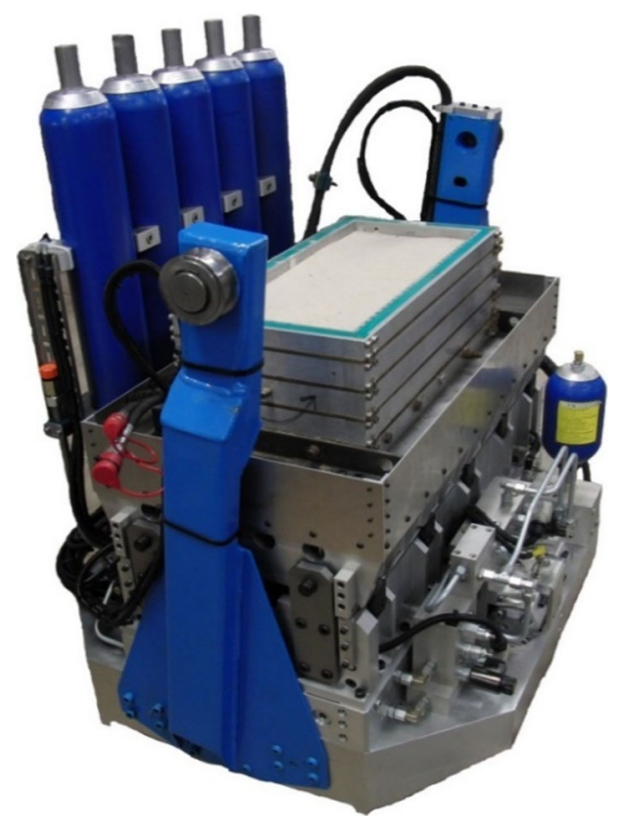

Fig. 6 A view of the servo-hydraulic earthquake actuator more realistic earthquake motions shown in Fig. 7a, b. It must be pointed out that for liquefaction-related problems strong, sinusoidal motions of $>0.1 \mathrm{~g}$ (at prototype scale) are quite effective as such motions are able to generate sufficient excess pore pressures to cause complete liquefaction of a saturated soil bed. However, for liquefaction problems, the ESB model container shown in Fig. 6 is less effective and can lead to some spurious wave reflections from the boundaries normal to direction of shaking. For the centrifuge tests described in this paper, a laminar model container [27] was utilised. A view of the laminar model container is presented in Fig. 8 that has internal dimensions of $500 \mathrm{~mm} \times 250 \mathrm{~mm} \times 300 \mathrm{~mm}$. This represents a soil body that is $25 \mathrm{~m}$ long $\times 12.5 \mathrm{~m}$ wide $\times 15 \mathrm{~m}$ deep at prototype scale. This is larger than the largest soil body that can be tested in shaking table tests such as the E-Defence shaking table facility in Japan. The individual laminae are separated by cylindrical roller bearings so that they can slide easily in the direction of shaking. A rubber membrane made of thin latex is utilised in liquefaction tests to retain the pore fluid within the saturated soil at high gravity. Further during liquefaction tests, the pore fluid is required to be $N$ times more viscous than water due to the scaling law requirements [23]. This is to ensure that the dynamic loading rate due to earthquake loading and consequent time it takes to generate the excess pore pressure and rate of reconsolidation of the liquefied soil match. For the tests described in this paper that were carried out at $50 \mathrm{~g}$, methyl cellulose was used to create a pore fluid that is 50 times more viscous than water. The Cam-Sat system [28] was used for computer-controlled saturation of the soil samples with the methyl cellulose fluid.

\section{Modelling of Earthquake Drains Using Recycled Brick Rubble}

\section{Earthquake Drain Material}

As explained earlier, the main aim of this paper is to mitigate liquefaction risk to structures both existing ones and new builds, using sustainable materials. Particular focus is given to the use of recycled materials such as 
Fig. 7 a Scaled Kobe motion in a $50 \mathrm{~g}$ centrifuge test,

b Imperial Valley motion in a $50 \mathrm{~g}$ centrifuge test

(a)
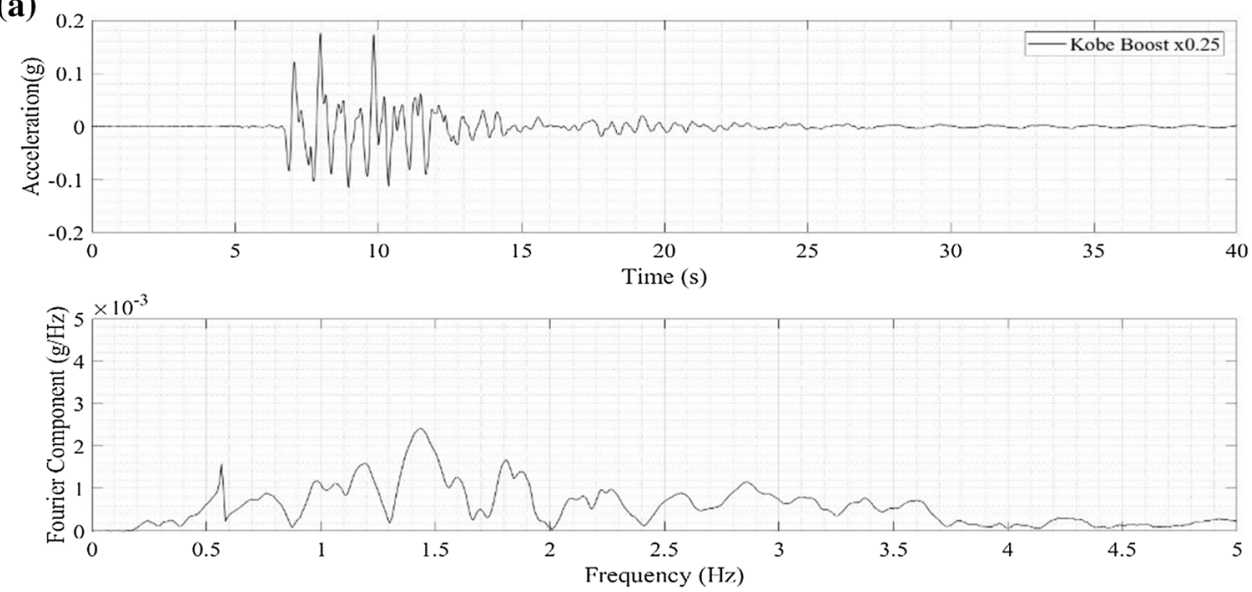

(b)
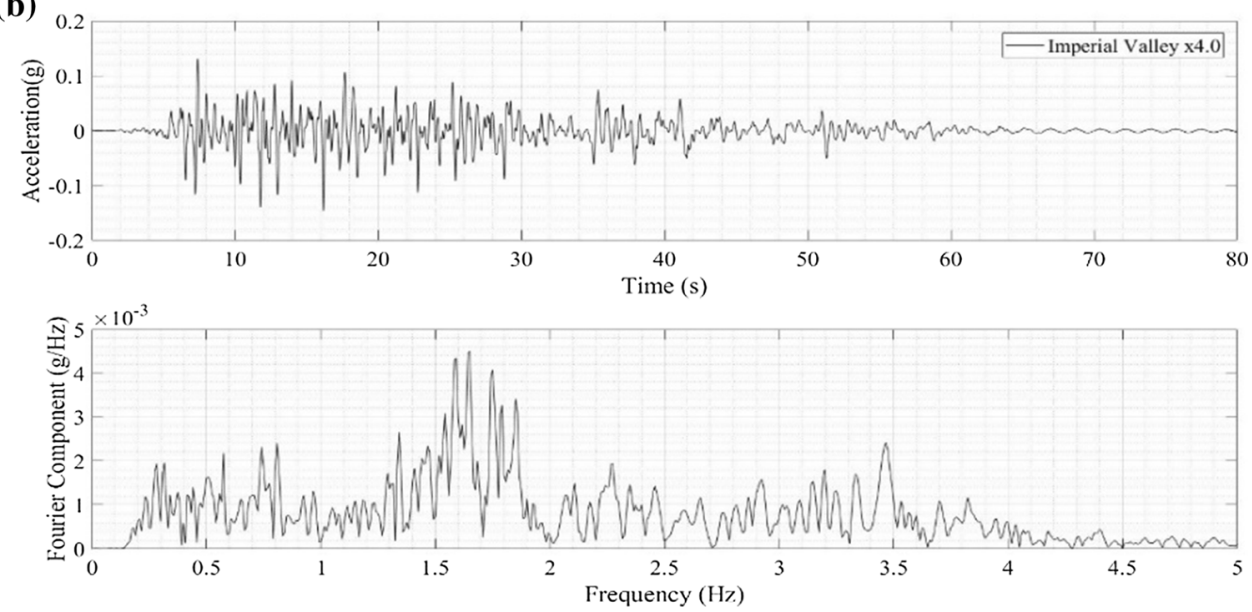

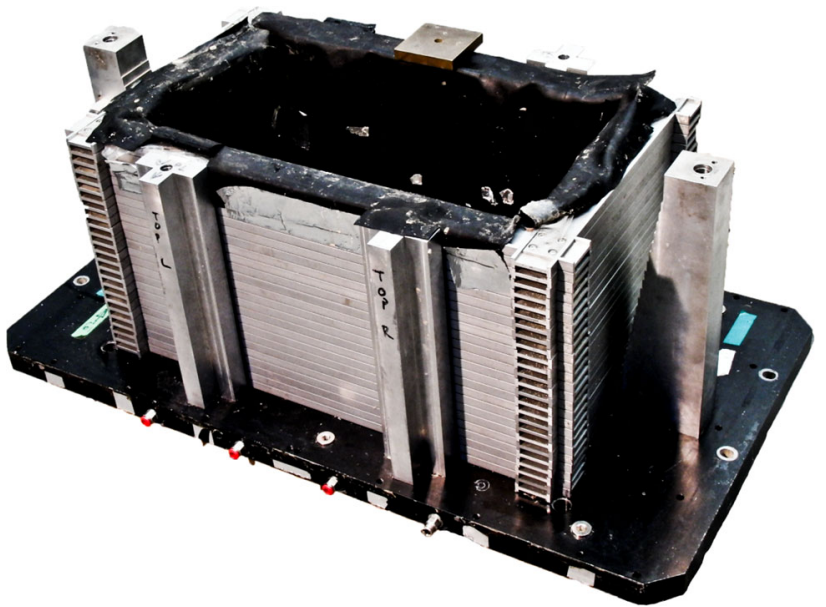

Fig. 8 A view of the laminar model container

construction debris. For this research, rubble bricks were chosen as earthquake drain material. A view of the model rubble bricks is shown in Fig. 9. The host liquefiable material used in this research was Hostun F65 sand, which is widely used for liquefaction problems at Cambridge.

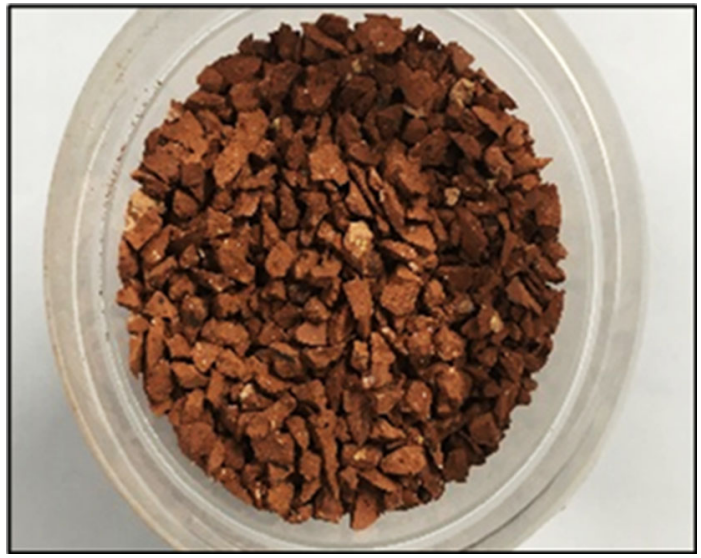

Fig. 9 A view of the rubble brick used for model earthquake drains

The particle size distribution curves for the rubble brick and the Hostun sand are shown in Fig. 10 and their salient characteristics are presented in Table 1. From these, it can be seen that the Hostun sand is quite fine with a $D_{50}$ size of about $0.4 \mathrm{~mm}$, while the $\mathrm{D}_{50}$ of the rubble brick was about $2.5 \mathrm{~mm}$, making it a suitable material for modelling 


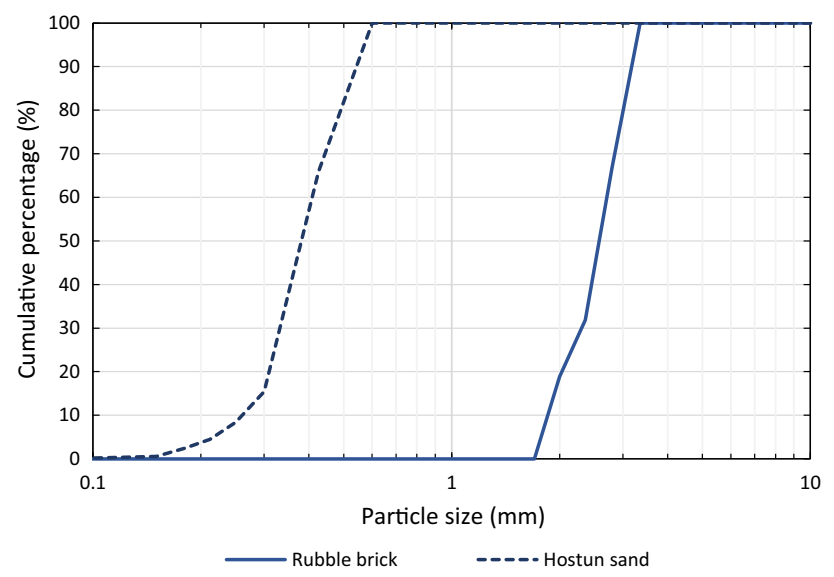

Fig. 10 Particle size distribution curves

Table 1 Properties of soil

\begin{tabular}{lll}
\hline Property & Hostun sand & Rubble brick \\
\hline Maximum void ratio, $e_{\max }$ & $0.648^{\mathrm{a}}$ & 1.45 \\
Minimum void ratio, $e_{\min }$ & $1.041^{\mathrm{a}}$ & 0.87 \\
Specific gravity, $G_{\mathrm{s}}$ & $2.65^{\mathrm{a}}$ & 2.50 \\
Average particle size, $D_{50}: \mathrm{mm}$ & 0.39 & 2.5 \\
Relative density, $D r: \%$ & 44 & 46 \\
Permeability, $k: \mathrm{mm} / \mathrm{s}$ & 1 & 5
\end{tabular}

a. [29]

earthquake drains. A view of the completed drains prior to saturation is shown in Fig. 11.

\section{Centrifuge Model Sections}

In this research, it was decided that in each centrifuge model two foundations will be tested. One of the foundations was located on liquefiable soil and an identical

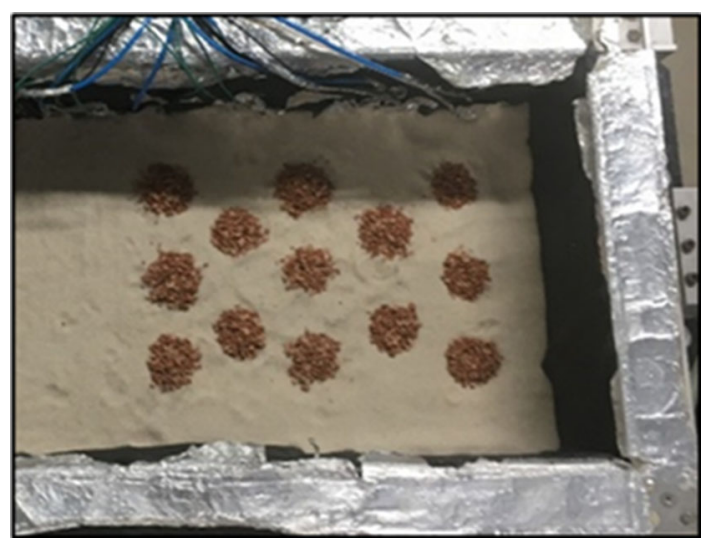

Fig. 11 Plan view of the rubble brick drains in Hostun sand in the laminar container foundation was located on a region improved by the earthquake drains. This would enable a direct comparison of the performance of the two foundations in terms of their accelerations and settlements. Further, the excess pore pressure generation and dissipation can be investigated in regions below each of the foundations, i.e. improved and unimproved. Earthquake drains as described previously were constructed within a centrifuge model as shown in Fig. 12. In constructing the centrifuge models, the Hostun sand was air-pluviated at the required relative density of $\sim 40 \%$. The form work for the drains is already in place and the drain material was poured and compacted by light tamping after the sand layer was poured to the required height. It must be noted that in this model construction procedure, the locking-in of horizontal stresses that is obtained when drains are constructed in the field is not captured. Also the relative density of the sand in between the drains will be the same as that in the free field. In Fig. 12, the foundations on the improved and unimproved ground are also seen. In Fig. 12a, the cross-sectional view is presented, while Fig. $12 \mathrm{~b}$ shows the plan view of the drains. The dimensions of the model are presented at the prototype scale. The soil body itself was instrumented with miniature accelerometers and pore pressure transducers. The locations of these instruments are also shown in Fig. 12. The model foundations were instrumented to measure the lateral accelerations and settlements using LVDT's.

\section{Dynamic Response of the Foundations}

From a structural performance point of view, it is important to understand the difference that the ground improvement makes in terms of the dynamic response of the structure. It has been previously seen that mitigating the liquefaction risk by using densification methods [30] or increasing the foundation soil stiffness using soil calcification methods (e.g. MICP [31]) can lead to increased transmission of accelerations to the structure. The vertical bearing pressure exerted by both the foundation blocks in these centrifuge tests was $50 \mathrm{kPa}$, which is the typical bearing pressure used for design of foundations for a medium sized structure.

\section{Acceleration-Time Histories}

In Fig. 13, the horizontal acceleration recorded on the foundation blocks placed on the region improved by drains and on the unimproved ground (see Fig. 12) are presented. The input acceleration applied at the bedrock level are also shown in Fig. 13. It can be seen that peak acceleration of $0.18 \mathrm{~g}$ applied at the bedrock is significantly attenuated by the time they reach the foundation blocks in both cases. 


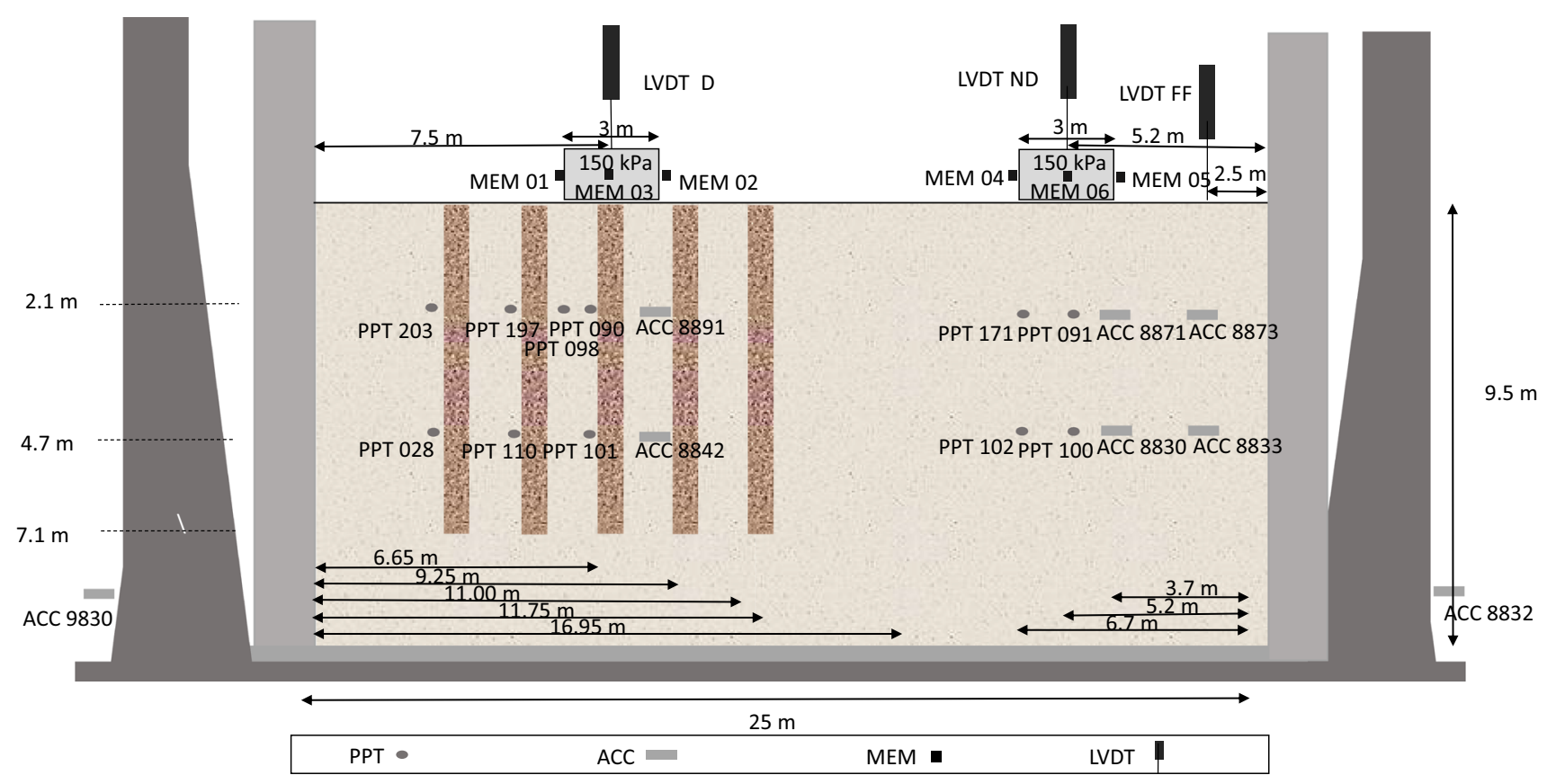

(a) cross-sectional view

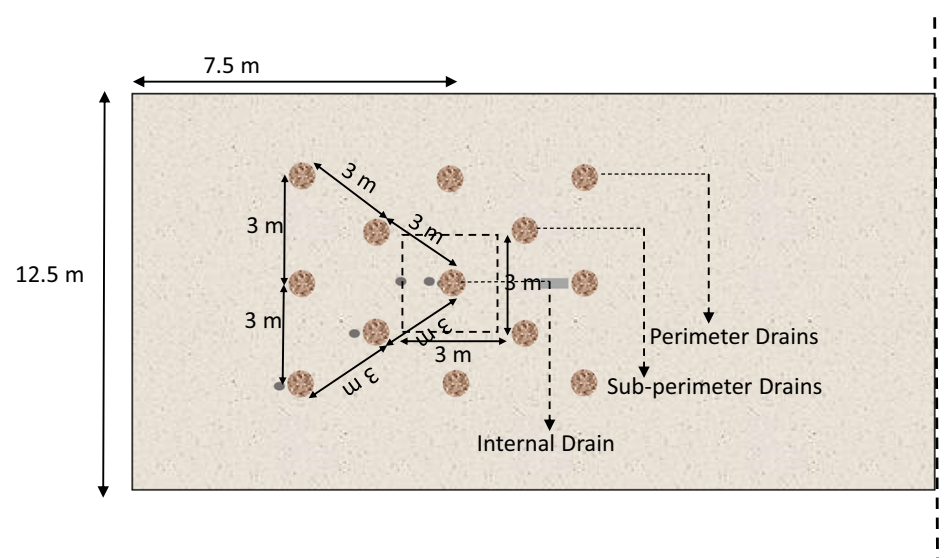

(b) plan view

Fig. 12 Typical sections of the centrifuge model

This is due to the loss of soil strength owing to liquefaction. The accelerations are slightly larger for the improved case compared to the unimproved case particularly in the latter cycles of shaking. This suggests that use of earthquake drains will result in a slightly larger shaking of the structure, but the increase is marginal.

\section{Settlement \& Rotation of the Foundations}

An important aspect of structural performance is the settlement and rotations that the foundations undergo due to soil liquefaction. In Fig. 14, the settlement-time history recorded by the LVDTs on the foundations placed on improved and unimproved regions (see Fig. 12) are presented. In this figure the long term settlement response of the foundations is shown. It is seen in this figure that the foundation block on the improved region settles about $400 \mathrm{~mm}$ while that on the unimproved soil settles by more than $625 \mathrm{~mm}$. The settlement of the free-field soil is also shown in this figure, which is about $210 \mathrm{~mm}$. The free-field soil settles less as there is no bearing pressure applied on this soil. It is also interesting to note that most significant settlements occur during the shaking phase of the earthquake, and much smaller settlements occur in the postseismic phase. Similar observations were previously made by Coelho et al. [30] and Madabhushi and Mitrani [31]. It must be pointed out that while the decrease in maximum settlement for the improved case is attractive, it is still too 
(a)

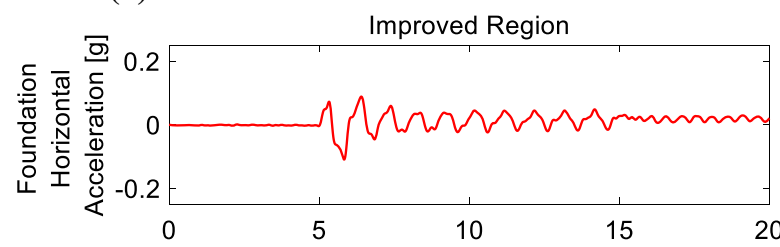

(c)

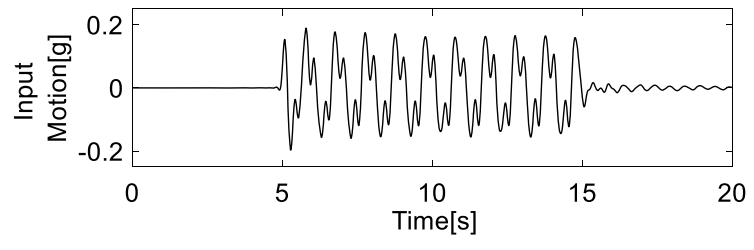

(b)

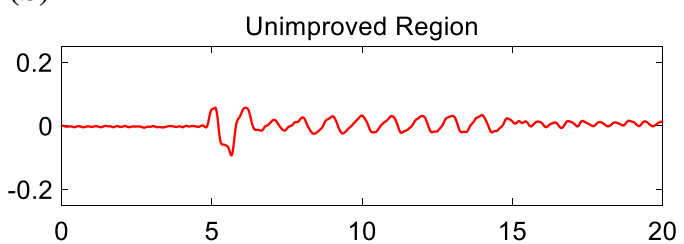

(d)

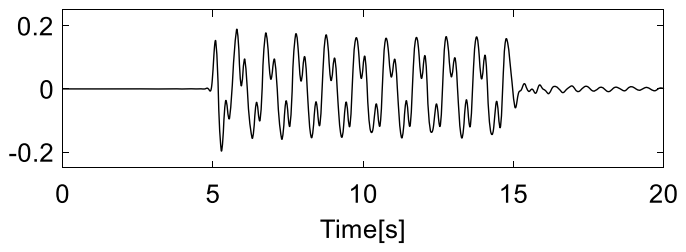

Fig. 13 Acceleration-time histories of the foundation

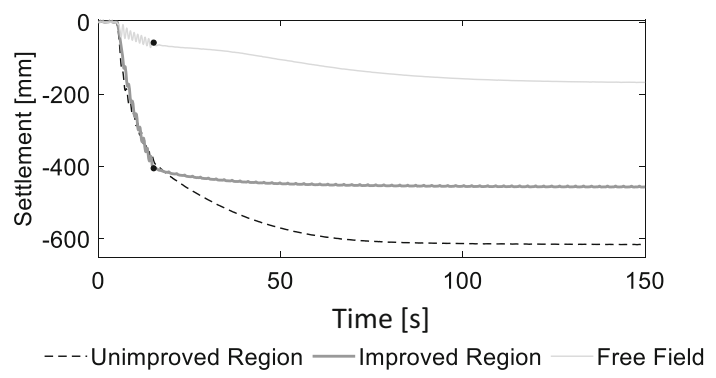

Fig. 14 Settlement of the foundations

large from a structural point of view. One aspect that is not modelled in this research is the densification induced increase in horizontal stresses imparted by the construction of the earthquake drains in the field cases [11]. As the model drains are constructed at $1 \mathrm{~g}$ prior to application of centrifugal accelerations, the increase in horizontal stresses are marginal. Thus the foundations may perform better in the field due to the additional horizontal stresses around the drains, but this aspect needs further research.

It would be interesting to see the rotations suffered by the two foundation blocks. Using the two vertical MEMS accelerometers shown in Fig. 12, it is possible to obtain the rotations suffered by the foundation blocks. The rotationtime histories are presented in Fig. 15 which show relatively large rotations to occur in the first few cycles of shaking, which rapidly subside with the onset of liquefaction. The rotations in the case of foundation block on improved zone are larger in the initial cycles compared to the unimproved case. The rotations of the foundations are plotted against settlements in Fig. 15. Again the decrease in magnitude of the rotation cycles with settlement is clearly seen. This may be due to the additional rotational stiffness gained by the foundation as it settles into the liquefied ground. In the presence of drains, this rotational stiffness increase is greater due to the shear reinforcement effects of the drain material. This resulted in a greater reduction of the rotations in later cycles of the earthquake loading and with increase in settlement of the foundation as seen in Fig. 15.

\section{Soil Response}

The dynamic response of the soil body in the unimproved region can be directly compared to that in the improved region using instrumentation shown in Fig. 12. Miniature accelerometers and pore pressures were placed close to the drains in the improved region at the same elevations as the instruments in the unimproved region.

\section{Acceleration-Time Histories}

The accelerations measured at two different depths $(2.1 \mathrm{~m}$ and $4.7 \mathrm{~m}$ ) below the foundation are presented in Fig. 16 for the improved region with drains and the unimproved region. In both cases, it can be seen that the accelerations are severely attenuated as they propagate upwards towards the soil surface. Comparing the two regions, it is also seen that the attenuation is more in the unimproved region. This is consistent with the observations made earlier with respect to the horizontal accelerations measured on the two foundation blocks. This type attenuation in accelerations is consistent with the liquefaction of the soil and loss of shear strength of soil with the onset of high excess pore pressures.

\section{Excess Pore Pressures}

The high excess pore pressures recorded at the same depths as the accelerations are presented in Fig. 17 for a period of $150 \mathrm{~s}$ to observe both the generation and dissipation of the excess pore pressures. For the foundation on the improved 
(a)

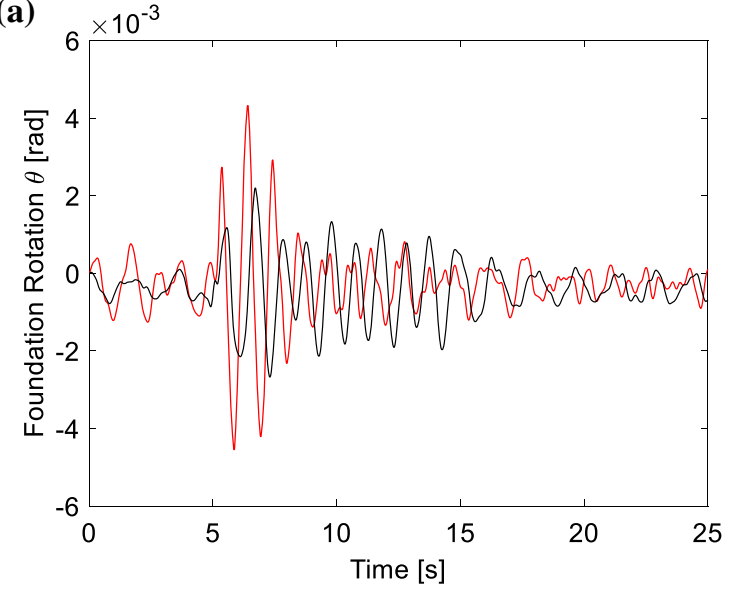

(b)

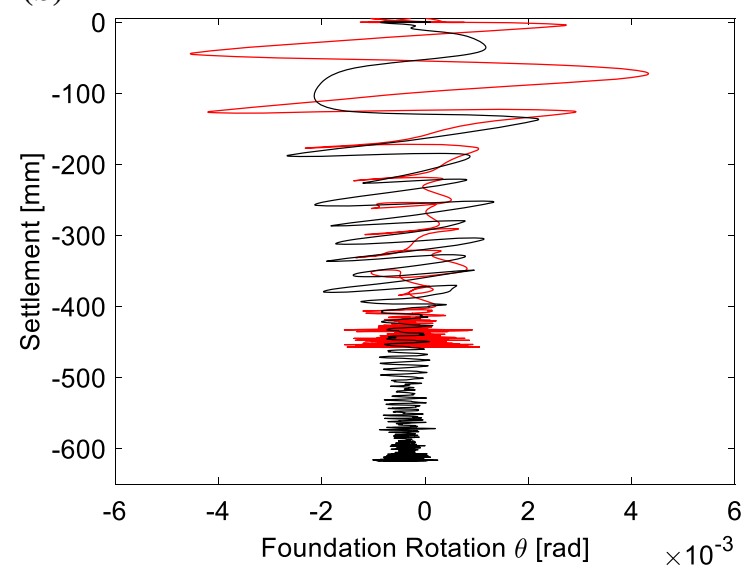

Improved Region __ Unimproved Region

Fig. 15 Rotation of the foundation

Fig. 16 Acceleration $(g)$ in the soil column below the foundation (a)

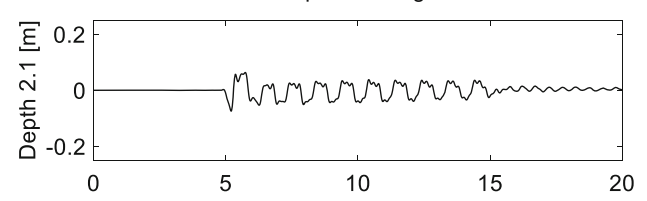

(c)
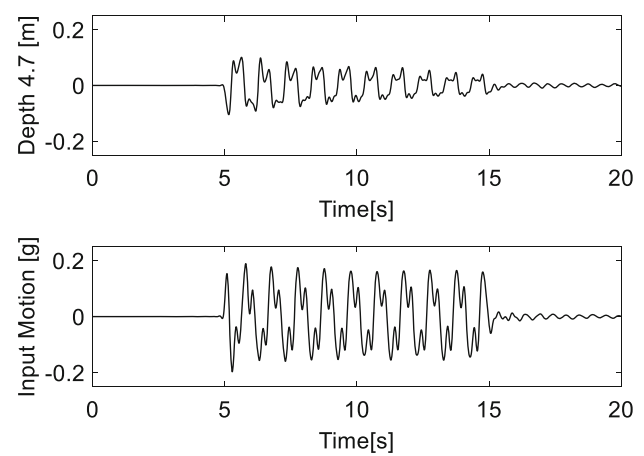

(b)

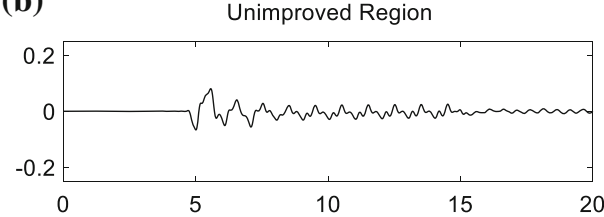

(d)
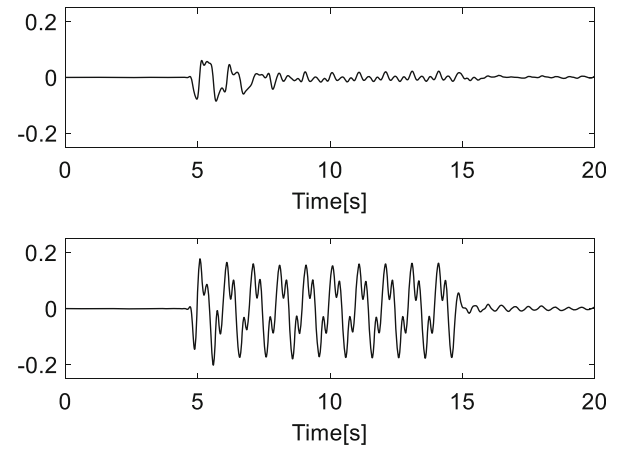

zone the excess pore pressures are plotted for different locations such as directly below the foundation, close to the semi-perimeter and perimeter drains. The start of the dissipation is plotted as 'dots' in these plots. In the unimproved region there were less number of pore pressure transducers (see Fig. 12) and hence the pore pressures below the foundation and at the edge of the foundation are plotted in Fig. 17. It can be seen that for the improved case the excess pore pressures are smaller below the foundation and up to the semi-perimeter drains. The perimeter drains see larger excess pore pressures as they are overwhelmed with the pore fluid migrating from the free field. Similar observations were also made by Brennan and Madabhushi $[7,12,13]$. In the unimproved region, the excess pore pressures continue to rise in the post-seismic period as more pore fluid migrates from the free field in the absence of any drains. Excess pore pressures are also retained longer due to the pore fluid migrating from deeper levels towards the ground surface. This may be the reason for a larger ultimate settlement of the foundation block on the unimproved ground, seen in Fig. 14.

\section{Excess Pore Pressure Contours}

The excess pore pressure dissipation data presented in Fig. 17 can be better visualised by plotting the excess pore pressure contours at different time instants as shown in Fig. 18. In order to construct these contours only the excess pore pressures at the depth of $2.1 \mathrm{~m}$ below the foundation was considered and the contours represent the excess pore pressures on a horizontal plane at this depth. In Fig. 18 it can be clearly seen that the excess pore pressures were 
(a)

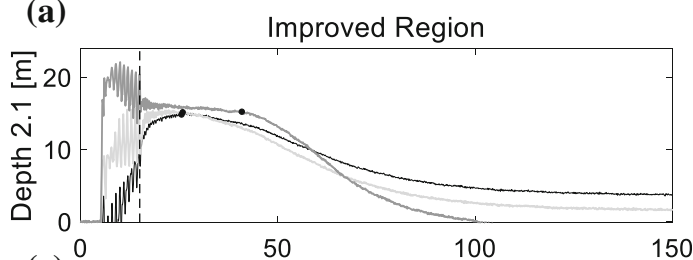

(b)

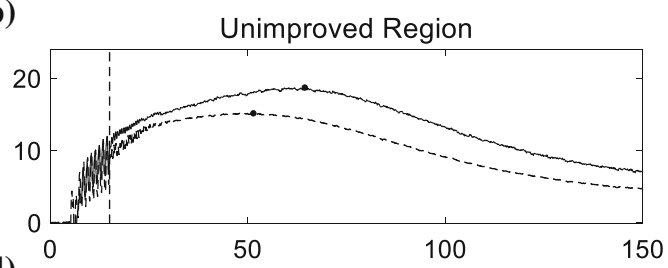

(d)

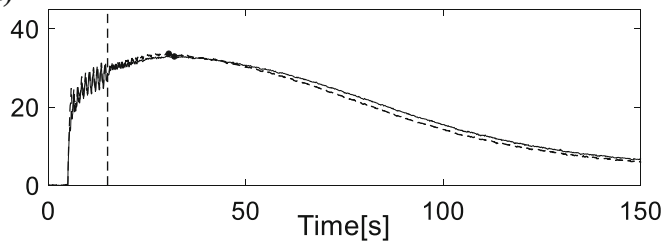

-Below Foundation ---.Foundation Edge

Semi-Perimeter Drain —-Perimeter Drain
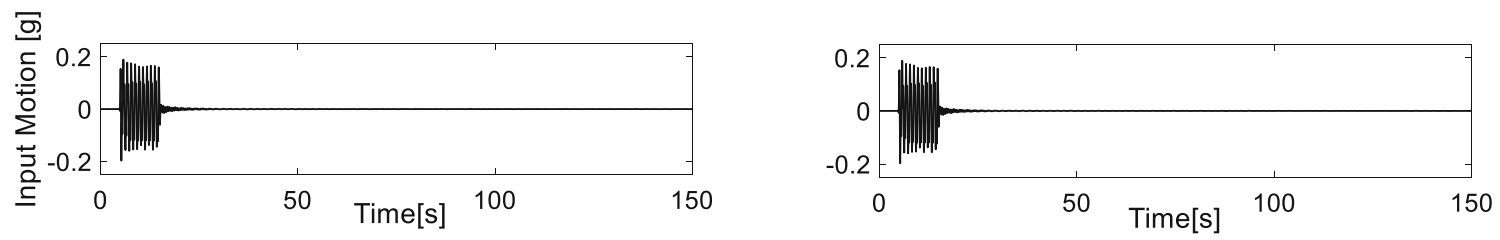

Fig. 17 Excess pore pressures $(\mathrm{kPa})$ at different depths below the foundation

higher in the outer regions of the plot at the end of shaking. As time goes by the excess pore pressures dissipate everywhere. However, the region below the foundation block sees lower excess pore pressures throughout this time period. In contrast in the unimproved zone the excess pore pressures were higher below the foundation, they increase immediately in the post-seismic period due to the pore fluid migration and are retained for longer, causing the foundation to settle more.

\section{Numerical Modelling of Earthquake Drains}

The problem of earthquake drains is quite a complex one to model numerically. Although there are a few attempts at modelling the problems in plane strain, i.e. assuming wall drains instead of individual drains [14], there is very little research on this topic. The problem of earthquake drains is a 3D problem with pore water flow occurring in both lateral and vertical directions towards the drains. In addition, the problem of modelling earthquake induced liquefaction can be only carried out in non-linear time domain finite element analyses. Further, sophisticated constitutive models that allow for the plastic volumetric and shear strains in the soils in response to the earthquake loading, are required. In this research, the first part of the problem is addressed i.e. the $3 \mathrm{D}$ nature of the earthquake drains.

Using standard ABAQUS platform it is possible to carry out coupled analyses that link the solid and fluid phases of the saturated soil medium. This can be used to solve consolidation problems in soil mechanics. In this paper, this platform is used to model the earthquake drains in a fully $3 \mathrm{D}$ mesh. However, the generation of the excess pore pressures during earthquake loading cannot be modelled in ABAQUS. Instead the excess pore pressures observed in the free field during centrifuge tests are fed, in a functional form, as boundary conditions to the 3D FE mesh and the post-seismic reconsolidation is modelled. This procedure, if sufficiently accurate, can be a way forward to model drainage problems in liquefied soil without the need to model the earthquake loading and excess pore pressure generation fully.

\section{Finite Element Discretisation}

The soil domain formed by the Hostun sand and the earthquake drains formed by the rubble bricks were discretised using 3D brick elements using an unstructured mesh approach as shown in Fig. 19. In order to reduce the run time in ABAQUS the soil domain was reduced in plan area as shown in Fig. 19 for some of the analyses. The soil properties outlined in Table 1 were used in these analyses. The variation of co-efficient of consolidation and permeability at very low effective stresses for the Hostun sand were adopted from Haigh et al. [29] and Adamidis and Madabhushi [32].

As explained earlier, the 3D FE analyses were carried out utilising the excess pore pressures recorded in the free field during the centrifuge tests. In Fig. 20, a functional form that was used to fit excess pore pressures generated at 

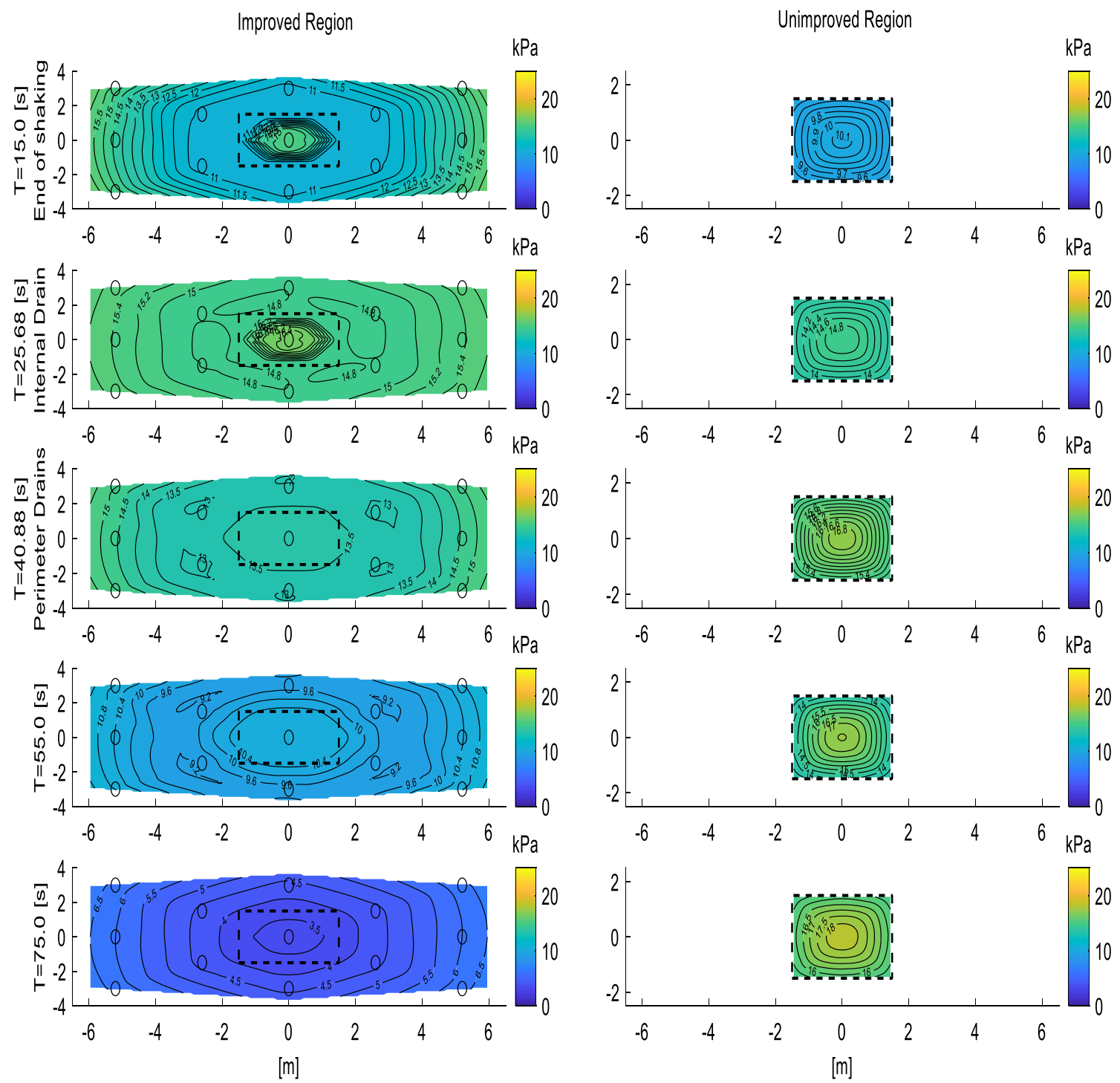

Fig. 18 Excess pore pressure contours at different times $2.1 \mathrm{~m}$ below the foundation

various depths is presented. In addition to the values of excess pore pressures, the boundary conditions were prescribed to the function i.e. zero excess pore pressure at the surface and the normality rule at the bedrock, so that no flow could occur at the bedrock level. The best fit trend line shown in Fig. 20 has an excellent correlation factor of $R^{2}=1$. This functional form was then used to apply the excess pore pressures at the boundary fluid nodes at all depths. The reconsolidation analyses of the soil domain shown in Fig. 19 were then carried out and the excess pore pressures at various internal nodes at which excess pore pressures were monitored during the centrifuge tests along with the settlement of the foundation block.

The excess pore pressure ratios obtained close to the internal drain and the sub-perimeter drain are presented in Fig. 21. In this figure, the excess pore pressure ratios from the centrifuge model tests that were described earlier are plotted along with the results from the numerical analysis. The comparison between the two modelling techniques is satisfactory, particularly given the simplifications made in the numerical modelling. The 3D FE analyses is able to capture the lower excess pore pressure ratios close to the internal drain and the higher excess pore pressures close to the sub-perimeter drains. This suggests that the horizontal and vertical excess pore fluid migration is being captured satisfactorily in this analysis.

It is also possible to compare the settlement of the foundation block observed in the centrifuge testing to the numerical prediction. In Fig. 22 the two settlement-time histories are presented. In the centrifuge test the foundation settlement shows step-like trace during earthquake shaking after which it settles smoothly by a small amount. These 

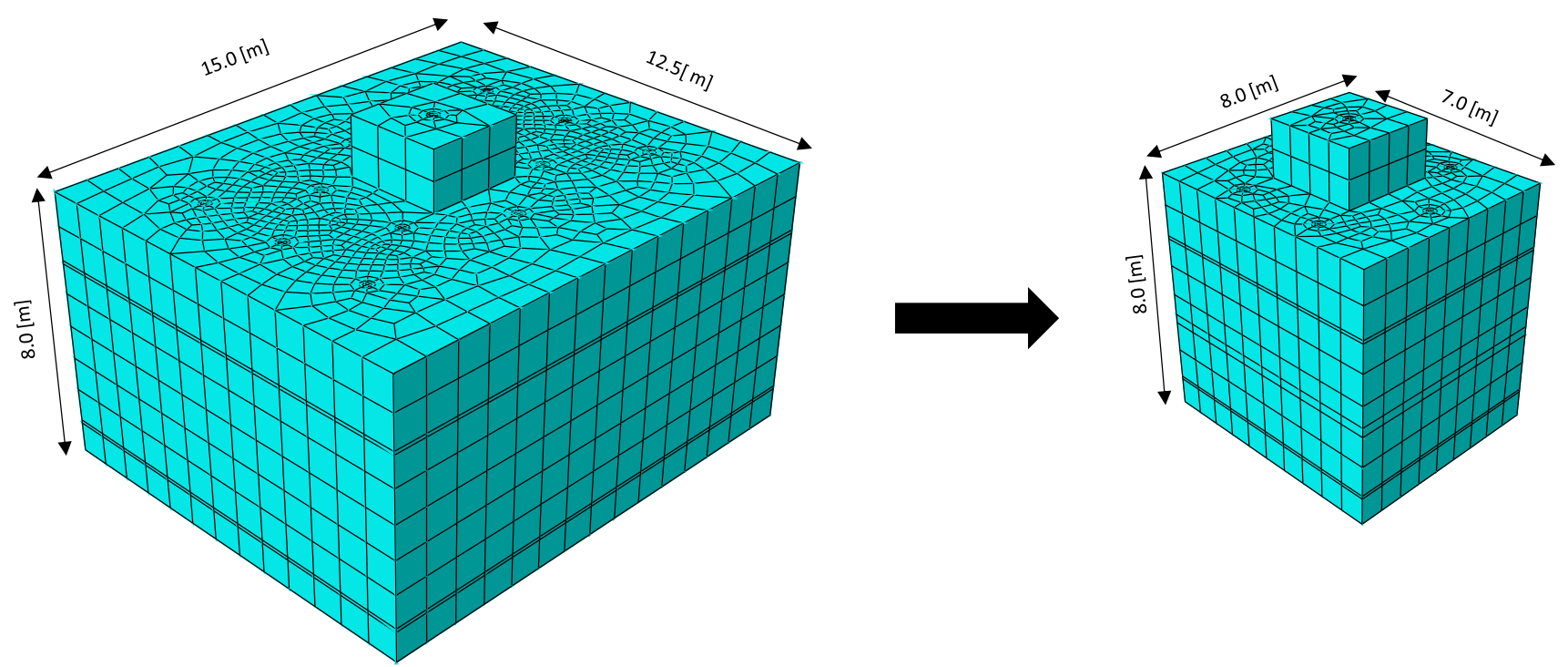

Fig. 19 3D Finite element discretisation

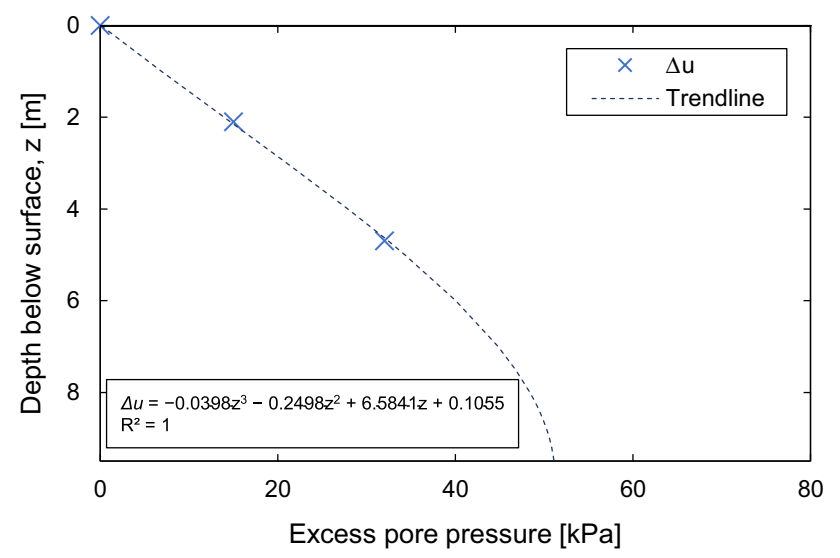

Fig. 20 Functional form of the excess pore pressure profile before continuing to settle during the positive spikes in excess pore pressure. This is a dynamic phenomenon. In the numerical analyses, the settlement during the seismic period does not show any steps and is rapid. This is attributed to the fact that, while excess pore pressures are being simulated in these analyses, no dynamic phenomena are being modelled. However, the overall settlements both during the co-seismic period and the post-seismic period compare satisfactorily. This suggests that the softening of the soil due to the excess pore pressure magnitude is sufficient to capture the foundation block settlement, at least in terms of magnitudes. This methodology can therefore be used to estimate the settlements from a preliminary design perspective.

steps are attributed to relative regaining of soil stiffness due to the oscillations in the excess pore pressures (suction spikes) due to which the foundation settlement slows down,

Fig. 21 Excess pore pressure ratio from centrifuge tests and numerical modelling
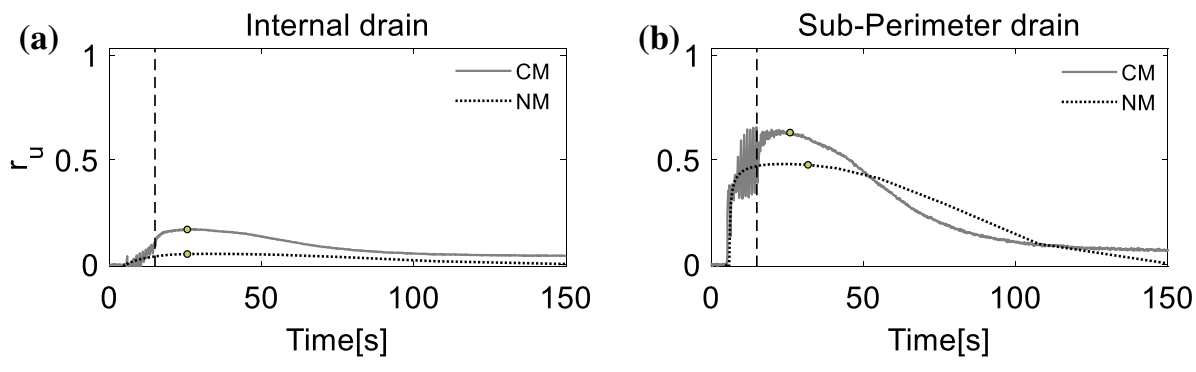

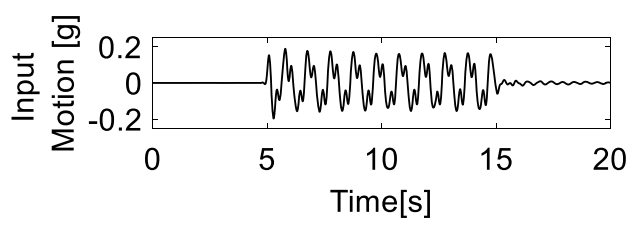




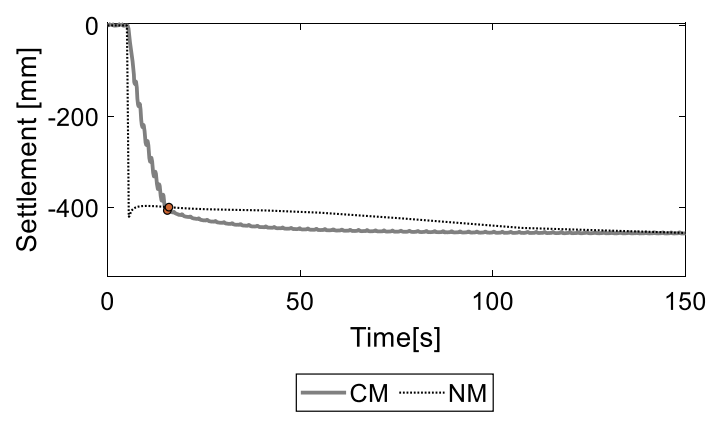

Fig. 22 Foundation settlement from centrifuge test and numerical modelling

\section{Conclusions}

Soil liquefaction caused by earthquake events can cause severe damage to structures. In this paper, the main focus has been on mitigating the liquefaction risk for small to medium-sized structures using sustainable techniques. In this research, rubble brick was used to construct the model drains, which can be considered as a sustainable material due to its abundance from construction debris. The use of earthquake drains to mitigate liquefaction risk was demonstrated previously for level grounds with no structures. In this paper, the presence of the foundations of a structure over a zone of liquefiable soil improved using earthquake drains was considered. The efficacy of these drains in the presence of structures was investigated using dynamic centrifuge testing by a direct comparison between foundation blocks on improved and unimproved regions in the same centrifuge model.

It was shown that the presence of earthquake drains can reduce the ultimate settlement of the foundations. The horizontal accelerations felt by the foundation block are marginally higher compared to the foundation on an unimproved soil block. Similarly the rotation suffered by the foundation during initial cycles of an earthquake can be larger, but the rotation cycle amplitude reduces with increasing settlement. The excess pore pressures generated within the soil body at different elevations were monitored in both improved and unimproved regions. It was shown that smaller excess pore pressures were observed below the foundation in the improved region compared to unimproved region. This result was presented visually as excess pore pressure contours at different times.

Finally, a simplified procedure for carrying out 3D finite element analyses using ABAQUS was presented. These analyses were carried out by prescribing the excess pore pressures at different elevations in a functional form based on centrifuge testing. The excess pore pressures and the settlement from the numerical analyses compare satisfactorily to the centrifuge test data, at least in terms of magnitude. It was concluded such a simplified approach may be used to estimate the settlement of foundations located on improved ground with earthquake drains for preliminary design purposes.

Open Access This article is licensed under a Creative Commons Attribution 4.0 International License, which permits use, sharing, adaptation, distribution and reproduction in any medium or format, as long as you give appropriate credit to the original author(s) and the source, provide a link to the Creative Commons licence, and indicate if changes were made. The images or other third party material in this article are included in the article's Creative Commons licence, unless indicated otherwise in a credit line to the material. If material is not included in the article's Creative Commons licence and your intended use is not permitted by statutory regulation or exceeds the permitted use, you will need to obtain permission directly from the copyright holder. To view a copy of this licence, visit http://creativecommons.org/licenses/by/4.0/.

\section{References}

1. Gajan S, Kutter BL (2008) Capacity, settlement, and energy dissipation of shallow footings subjected to rocking. ASCE J Geotechn Geo-environ Eng 134(8):1129-1141

2. Gazetas G, Anastasopoulos I, Adamidis O, Kontoroupi T (2013) Nonlinear rocking stiffness of foundations. J Soil Dyn Earthq Eng 47:83-91

3. Heron CM, Haigh SK, Madabhushi SPG (2015) A new macroelement model encapsulating the dynamic moment-rotation behaviour of shallow foundations. Geotech Symp Geotech Earthq Eng 65(5):441-452. https://doi.org/10.1680/geot./SIP15-P-020

4. Pelekis I, Madabhushi SPG, DeJong MJ (2018) Seismic performance of buildings with structural and foundation rocking in centrifuge testing. J Earthq Eng Struct Dyn 47(12):2390-2409. https://doi.org/10.1002/eqe.3089

5. Jabary R, Madabhushi SPG (2015) The effects of tuned mass dampers observed in geotechnical centrifuge tests on multi-storey buildings. J Soil Dyn Earthq Eng 70:373-380

6. Boksmati JI, Madabhushi SPG (2020) Centrifuge modelling of structures with oil dampers under seismic loading. Earthq Eng Struct Dyn J 49(4):356-374. https://doi.org/10.1002/eqe.3243

7. Brennan AJ, Madabhushi SPG (2002) Effectiveness of vertical drains in mitigation of liquefaction. J. Soil Dyn Earthq Eng 22(9-12):1059-1065

8. Garcia-Torres S, Madabhushi SPG (2019) Performance of vertical drains in liquefaction mitigation under structures. Bull Earthq Eng 17(11):5849-5866

9. Garcia-Torres S, Madabhushi SPG (2020) Inclined and vertical perimeter drains performance as liquefaction countermeasure techniques below existing buildings. J Earthq Tsunami. https://doi.org/10.1142/S1793431120500153

10. Seed BH, Booker JR (1977) Stabilization of potentially liquefiable sand deposits using gravel drains. J Geotech Eng Div 103(7):757-768

11. Raju VR, Wegner R, Krishna YH (2004) Ground improvement using vibro replacement in ASIA 1994 to 2004. A 10 year review. In: 5th international conference on ground improvement techniques, Kuala Lumpur, Malaysia

12. Brennan AJ, Madabhushi SPG (2005) Liquefaction and drainage in stratified soil. ASCE $\mathrm{J}$ Geotech Geo-Environ Eng 131(7):876-885

13. Brennan AJ, Madabhushi SPG (2006) Liquefaction remediation by vertical drains with varying penetration depths. J Soil Dyn Earthq Eng 26(5):469-475 
14. Howell R, Rathje EM, Kamai R, Boulanger R (2012) Centrifuge modeling of prefabricated vertical drains for liquefaction remediation. J Geotech Geoenviron Eng 138(3):262-271. https://doi.org/10.1061/(ASCE)GT.1943-5606.0000604

15. Olarte JC, Dashti S, Liel AB, Paramasivam B (2018) Effects of drainage control on densification as a liquefaction mitigation technique. J Soil Dyn Earthq Eng 110:212-231. https://doi.org/10.1016/j.soildyn.2018.03.018

16. Shenthan T, Nashed R, Thevanayagam S, Martin GR (2004) Liquefaction mitigation in silty soils using composite stone columns and dynamic compaction. Earthq Eng Eng Vib 3(1):39-50. https://doi.org/10.1007/BF02668849

17. Orense RP (2015) Liquefaction: countermeasures to mitigate risk. In Beer M, Kougioumtzoglou IA, Patelli E, Siu-Kui Au I (eds), Encyclopedia of earthquake engineering, pp 1-13. Springer, Berlin https://doi.org/10.1007/978-3-642-36197-5_19-2

18. Orense RP, Morimoto I, Yamamoto Y, Yumiyama T, Yamamoto H, Sugawara K (2003) Study on wall-type gravel drains as liquefaction countermeasure for underground structures. J Soil Dyn Earthq Eng 23(1):19-39

19. Bahadori H, Farzalizadeh R, Barghi A, Hasheminezhad A (2018) A comparative study between gravel and rubber drainage columns for mitigation of liquefaction hazards. J Rock Mech Geotech Eng 10(5):924-934

20. Hazarika H, Kohama E, Sugano T (2008) Underwater shake table tests on waterfront structures protected with tire chips cushion. ASCE J Geotech Geo-Environ Eng 134(12):1706-1719

21. Abdullah A, Hazarika H (2016) Improvement of shallow foundation using non-liquefiable recycle materials. Jpn Geotech Soc Spec Publ 2(54):1863-1867

22. Kumara, GHAJJ, Dilrukshi ALA, Subasinghe, NN (2008) Study on advantages of using coir dust in vertical drains for the improvement of soft clay. In: Haigh R, Amartunga D (eds) CIB international conference on building education and research, pp 1343-1357, ISBN 978-1-905732-36-4.

23. Madabhushi SPG (2014) Centrifuge modelling for Civil Engineers. CRC Press, Boca Raton
24. Madabhushi SPG, Schofield AN, Lesley S (1998) A new stored angular momentum (SAM) based earthquake actuator. In: Cenrifuge'98, international conference on centrifuge modelling, Tokyo, Japan

25. Madabhushi SPG, Haigh SK, Houghton NE, Gould E (2012) Development of a servo-hydraulic earthquake actuator for the Cambridge Turner Beam Centrifuge. Int J Phys Model Geotech 12(2):77-88

26. Zeng X, Schofield AN (1996) Design and performance of an equivalent-shear-beam container for earthquake centrifuge modelling. Geotechnique 46(1):83-102

27. Brennan AJ, Madabhushi SPG, Houghton NE (2006) Comparing laminar and ESB containers for dynamic centrifuge modelling. In: Proceedings of international conference on physical modelling in geotechnics centrifuge'06, Balkema, Rotterdam

28. Stringer ME, Madabhushi SPG (2009) Novel computer controlled saturation of dynamic centrifuge models using high viscosity fluids. ASTM Geotech Test J 32(6):53-59

29. Haigh SK, Eadington J, Madabhushi SPG (2011) Permeability and stiffness of sands at very low effective stresses. Geotechnique 62(1):69-75. https://doi.org/10.1680/geot.10.P.035

30. Coelho PALF, Haigh SK, Madabhushi SPG, O'Brien AS (2007) Post-earthquake behaviour of footings when using densification as a liquefaction resistance measure. Ground Improv J Special Issue on Ground Improvement techniques. 11(1), 45-53

31. Mitrani H, Madabhushi SPG (2010) Cementation liquefaction remediation for existing building. Ground Improv $\mathrm{J}$ 163(G12):81-94

32. Adamidis O, Madabhushi SPG (2016) Post-liquefaction reconsolidation of sand. Proc R Soc A Math Phys Eng Sci 472:20150745. https://doi.org/10.1098/rspa.2015.0745

Publisher's Note Springer Nature remains neutral with regard to jurisdictional claims in published maps and institutional affiliations. 